\title{
Conduction Mechanism and Dielectric Properties of Li-Zn Ferrites
}

\author{
S. M. Attia ${ }^{a}$ \& T. M. Meaz \\ ${ }^{a}$ Physics Department, Faculty of Science, Kaferelshikh University, \\ Kafer El-Shiekh, Egypt. \\ ${ }^{b}$ Physics Department, Faculty of Science, Tanta University, Tanta, Egypt.
}

Four samples of $\mathrm{Zn}_{1-x} \mathrm{Li}_{0.5 x} \mathrm{Fe}_{2+0.5 x} \mathrm{O}_{4}(x=0.25,0.5,0.75$, and 1) were prepared by the ceramic method. AC electrical conductivity and the dielectric constant were determined. High abnormal value of the dielectric constant $10^{11} \sim$ $10^{13}$ was a mean feature of such materials. The dielectric constant exhibits a sharp peaking behavior for some samples. The conduction mechanism was investigated and found to be multiple hopping conduction mechanism.

\section{Introduction:}

As a low-cost material, lithium ferrites are very attractive for microwave applications instead of garnets and other spinel ferrites [1]. Addition of different metal ions can control the properties of lithium ferrites for microwave applications. The crystal structure, microstructure and cation distribution have a remarkable effect on the ferrite properties and its applied aspects [2-4]. Several studies [1,5-8] have been reported on the effect of additions of divalent, trivalent and tetravalent ions on the electrical conductivity and dielectric properties of lithium ferrites. In this work the conduction mechanism and the dielectric properties of $\mathrm{Zn}_{1-\mathrm{x}} \mathrm{Li}_{0.5 \mathrm{x}} \mathrm{Fe}_{2+0.5 \mathrm{x}} \mathrm{O}_{4}$, where $\mathrm{x}=0.25,0.5$, 0.75 was undertaken

\section{Experimental Methods}

Highly pure chemical oxides were mixed together in a proper ratio to prepare $\mathrm{Zn}_{1-\mathrm{x}} \mathrm{Li}_{0.5 \mathrm{x}} \mathrm{Fe}_{2+0.5 \mathrm{x}} \mathrm{O}_{4}$, where $\mathrm{x}=0.25,0.5,0.75$, and 1 . The oxides were mixed together and ground to a very fine powder using an electric grounding machine. The grounding time was 6 hours for each sample. Then the mixture of each sample was pre-sintered at $900{ }^{\circ} \mathrm{C}$ for 6 hours in porcelain crucibles using an electric muffle furnace, and then left to cool to room temperature. The mixture was ground again for 6 hours to get a very ultra fine powder. The powders were, pressed (under pressure 20 bar) in die to get disc-shaped samples of diameter $1.2 \mathrm{~cm}$. The discs were sintered at $1150{ }^{\circ} \mathrm{C}$ for 6 hours and then left 
to cool to room temperature. Finally, the samples were polished to obtain two smooth uniform parallel disc surfaces. Contacts to the sample surface were verified by silver paste for electrical measurements. AC electrical conductivity and the dielectric properties of each sample were determined by using LCR meter (type- HIOKI 3532-50) in the frequency range $50 \mathrm{~Hz}-5 \mathrm{MHz}$ and in the temperature range from room temperature up to around $700 \mathrm{~K}$.

\section{Results and Dissections:}

AC electrical conductivity, $\sigma^{\prime}$, was measured at different temperatures $(\sim$ $300 \mathrm{~K}$ to $700 \mathrm{~K}$ ) in the frequency range $50 \mathrm{~Hz}-5 \mathrm{M} \mathrm{Hz}$ for $\mathrm{Zn}_{1-\mathrm{x}} \mathrm{Li}_{0.5 \mathrm{x}} \mathrm{Fe}_{2+0.5 \mathrm{x}} \mathrm{O}_{4}$ $\left(x=0.25,0.5,0.75\right.$, and 1.0). In (Fig. 1); the results show that $\sigma^{\prime}$ exhibits a semiconducting behavior with the temperature, i.e. the measured $\mathrm{AC}$ conductivity $\sigma^{\prime}$ increases with increasing temperature for all samples. This increase of $\sigma^{\prime}$ with temperature can be attributed to the increase of the drift mobility and/or hopping frequency of charge carriers. The samples of $x \geq 0.75$ show two different slopes as temperature increases. This behavior for $\mathrm{x}=1$ increases as frequency increases.
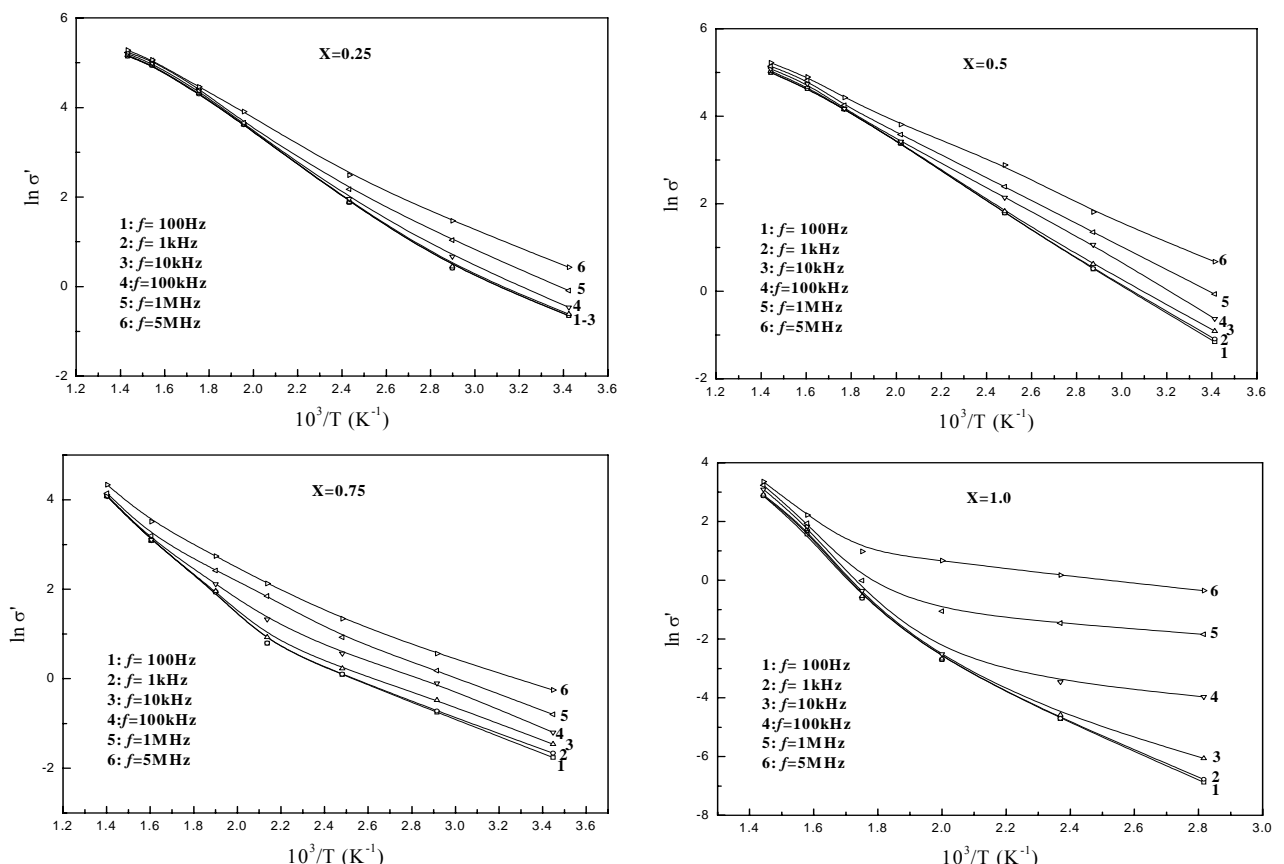

Fig. (1): The temperature dependence of $A C$ electrical conductivity, $\sigma^{\prime}$, at different frequencies for $\mathrm{Zn}_{1-\mathrm{x}} \mathrm{Li}_{0.5 \mathrm{x}} \mathrm{Fe}_{2+0.5 \mathrm{x}} \mathrm{O}_{4}$.

Figure (2) shows the variation of the measured AC electrical conductivity, $\sigma^{\prime}\left(\Omega^{-1} \mathrm{~m}^{-1}\right)$, with the frequency, $f(\mathrm{~Hz})$, as $\log$-log scale. It is also 
shown that $\sigma^{\prime}$ increases with increasing frequency for all samples. The same behavior was reported for other ferrites $[9,10]$. The dispersion in AC electrical conductivity of polycrystalline ferrites was explained on the basis of interfacial polarization that formed due to the inhomogeneous structure of ferrite material. According to Maxwell and Wagner model and Koops phenomenological theory [11], ferrite is imagined to act as a multilayer capacitor in which the ferrite samples are characterized by a microstructure consisting of conductive thick layers, grains (with conductivity $\sigma_{1}$; dielectric constant $\varepsilon_{1}$; and thickness $\mathrm{d}_{1}$ ) separated by resistive thin layers, grain boundaries (with $\sigma_{2} ; \varepsilon_{2}$; and $\mathrm{d}_{2}$ ). The impedance of this multilayer capacitor can be represented as [12].
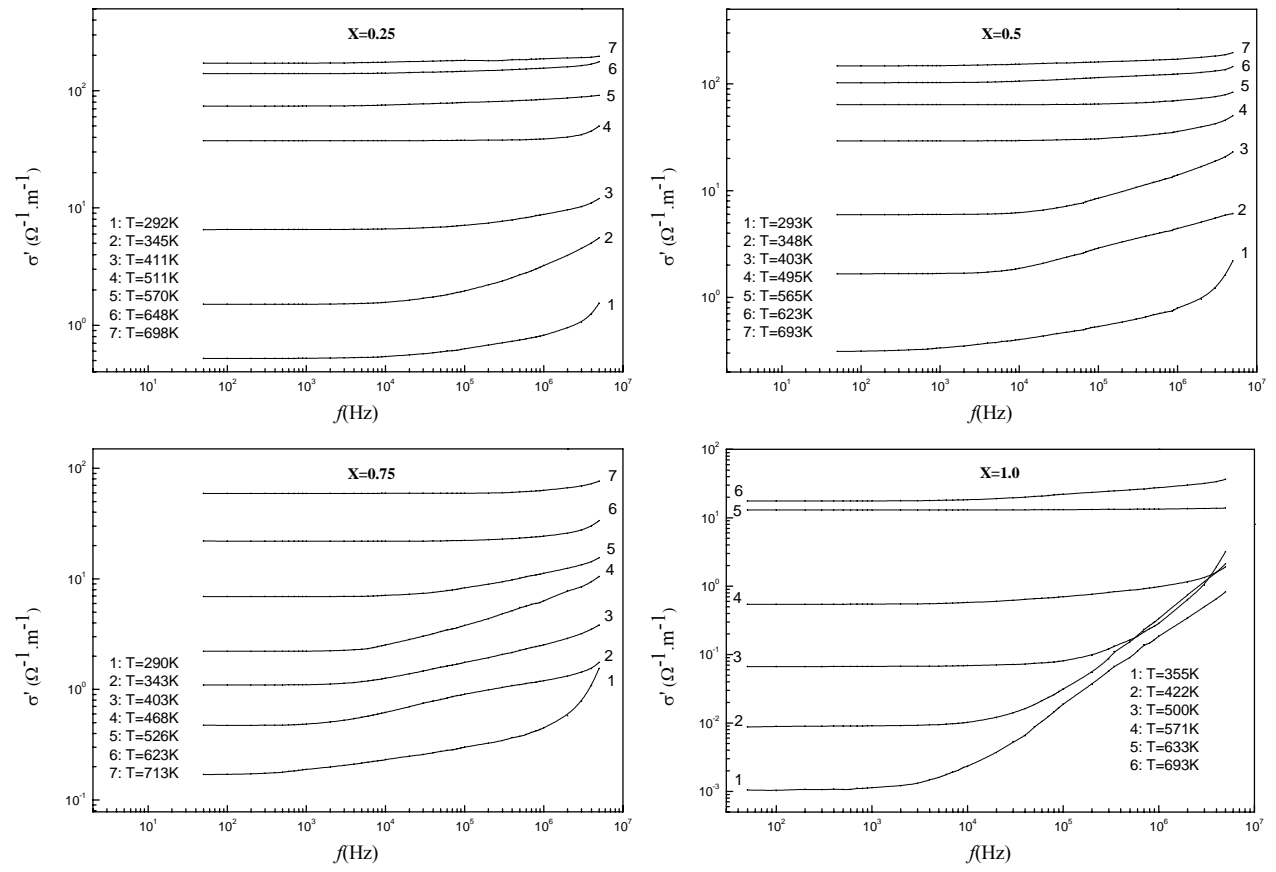

Fig. (2): AC electrical conductivity as a function of frequency at constant temperature for the samples of the system $\mathrm{Zn}_{1-\mathrm{x}} \mathrm{Li}_{0.5 \mathrm{x}} \mathrm{Fe}_{2+0.5 \mathrm{x}} \mathrm{O}_{4}$.

$$
\mathrm{Z}^{-1}=\mathrm{R}^{-1}+\mathrm{J} \omega \mathrm{C}
$$

where $\omega$ is the angular frequency $(\omega=2 \pi f), \mathrm{R}$ and $\mathrm{C}$ are the parallel equivalent resistance and capacitance of the material, respectively. According to Equation (1), it is shown that above a certain frequency, the inverse impedance of the multilayer condenser and hence AC conductivity of ferrite material rises with frequency. The measured electrical conductivity with the frequency $\sigma^{\prime}$ can be described by the following relation [13]. 


$$
\sigma^{\prime}=\sigma_{0}+\sigma_{\mathrm{AC}}
$$

where $\sigma_{\mathrm{o}}$ represents the conductivity at zero frequency, and $\sigma_{\mathrm{AC}}$ is the pure AC electrical conductivity. Equation (2) represents the total conductivity in the context of the theory of relaxation processes in dielectric materials, which is the classical way of studying AC conductivity in such material. The general behavior of $\sigma_{\mathrm{AC}}$ with the angular frequency $\omega(=2 \pi f)$ can be described by the following relation [14].

$$
\sigma_{\mathrm{AC}}=\mathrm{A} \omega^{\mathrm{s}}
$$

i.e. pure $\mathrm{AC}$ conductivity is proportional to $\omega^{\mathrm{S}}$, where $\mathrm{A}$ is a constant having the dimension of the conductivity and $\mathrm{s}$ is exponent constant. Therefore, equation (2) can be re-written as follows:

$$
\sigma^{\prime}=\sigma_{\mathrm{o}}+\mathrm{A} \omega^{\mathrm{s}}
$$

The results of the variation of $\mathrm{AC}$ electrical conductivity with the frequency were fitted according to equation (4) in order to calculate the frequency exponent s. However, it is difficult to predict the conduction mechanism in these materials through measurements of $\mathrm{AC}$ electrical conductivity as a function of the frequency only. Most of models of conduction mechanism can be predicted through the studying the behavior of the exponent $\mathrm{s}$ with temperature $\mathrm{T}$ [15]. The classical barrier model for single electron hopping between two localized states over a potential barrier separating the sites as well as the correlated barrier hopping ( $\mathrm{CBH})$ model suggested that s should decrease with increasing temperature. The quantum mechanical tunneling (QMT) model implies that $\mathrm{s}$ is temperature independent. In the case of small polaron (SP) model, s should increase with increasing the temperature. Finally, the large overlapping polaron (OLP) model suggested that $\mathrm{s}$ should decrease with increasing the temperature up to a certain temperature, after which $\mathrm{s}$ increases with further increase of the temperature [15].

By inspection of Fig (3), and in the light of the above argument, it is difficult to restrict the conduction mechanism for all samples to one of the above mentioned models. Multiple hopping conduction mechanism suggested that as the temperature increases a cluster of three, four, etc. sites could be formed through which a hopping may occur instead of a simple $\mathrm{Fe}^{3+}-\mathrm{Fe}^{2+}$ pair. Depending on the size of the cluster, the electron may hop many times during a half period of the external applied signal. The size of the cluster increases with increasing the temperature and can be defined by the thermal energy kT: According to the multiple hopping conduction mechanism, the electric conductivity can be written as $[16,17]$, 


$$
\sigma^{\prime}(\omega, \mathrm{T}) \propto \omega^{\mathrm{S}} \mathrm{T}^{\mathrm{d}}
$$

where the temperature parameter $\mathrm{d}$ depends on the composition and the frequency. The logarithmic representation of this equation is shown in Fig. (4), at certain selected frequencies $100 \mathrm{~Hz}, 1 \mathrm{kHz}, 10 \mathrm{kHz}, 100 \mathrm{kHz}, 1 \mathrm{MHz}$ and 5 MHz. It is shown that $\sigma^{\prime}$ increases with increasing temperature. The temperature parameter $\mathrm{d}$ was determined from the slopes of the lines and given in Table (1). The values of $d$ are always greater than unity. The multiple hopping weakens the frequency dependence but simultaneously strengthens the temperature dependence, so a multiple hopping mechanism becomes more important at lower frequency and high temperatures. These results are in a good agreement with the previously published results for $\mathrm{BaZn}_{2-\mathrm{x}} \mathrm{Mg}_{\mathrm{x}} \mathrm{Fe}_{16} \mathrm{O}_{27}$ ferrites [9].
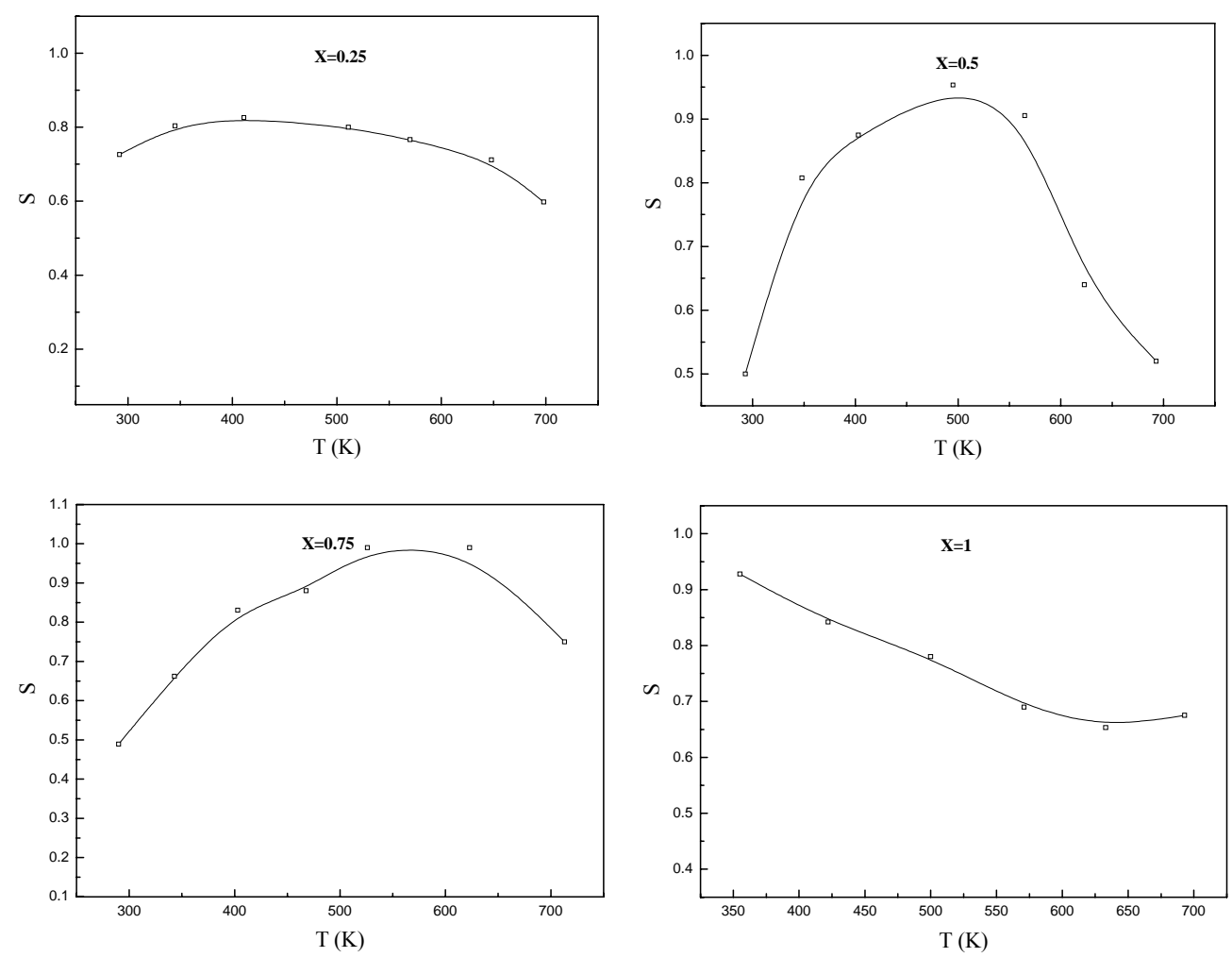

Fig. (3): Variation of the frequency parameter $\mathrm{s}$ with the temperature for samples of the system $\mathrm{Zn}_{1-\mathrm{x}} \mathrm{Li}_{0.5 \mathrm{x}} \mathrm{Fe}_{2+0.5 \mathrm{x}} \mathrm{O}_{4}$. 

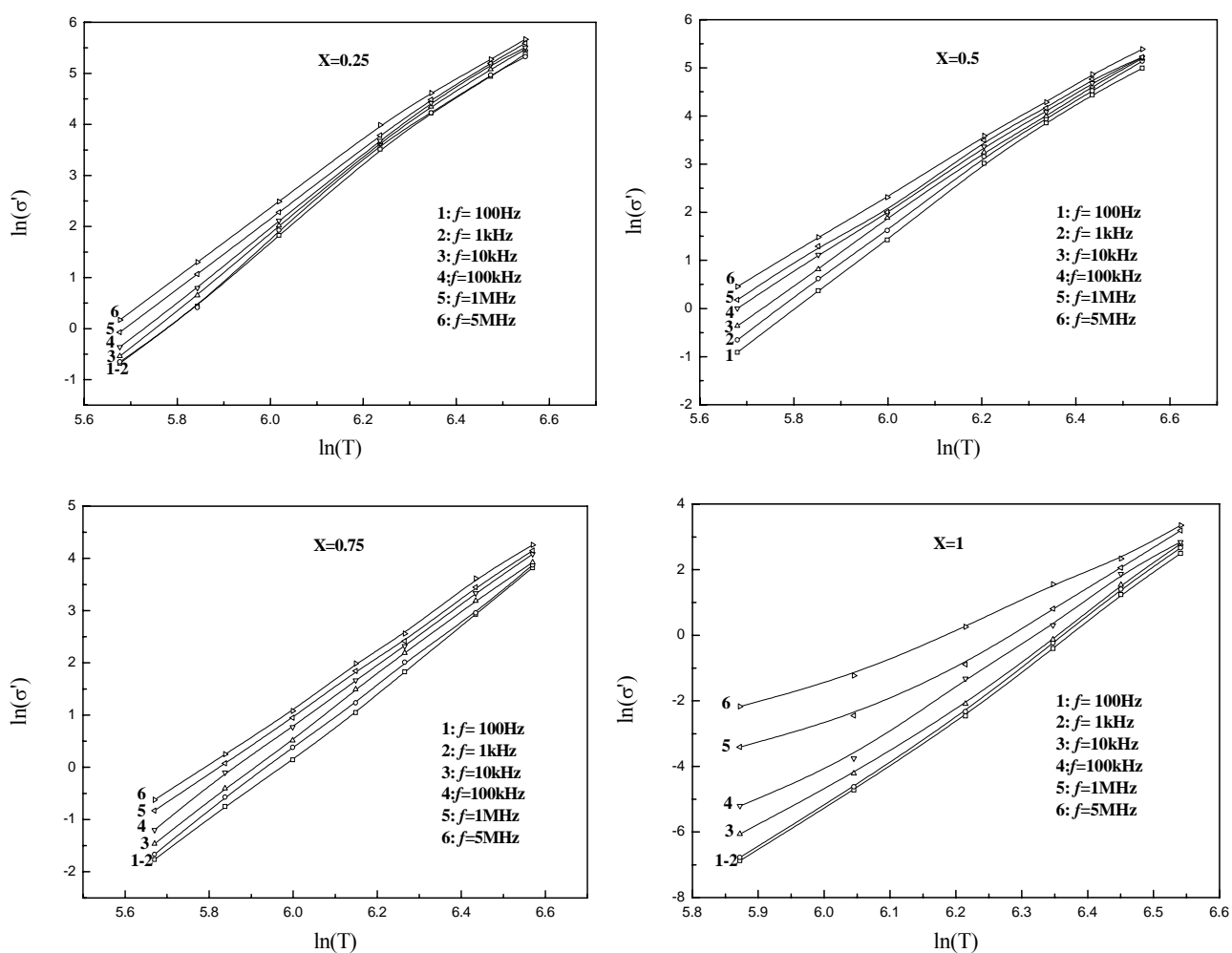

Fig. (4): Logarithmic representation of the temperature dependence of $A C$ conductivity at different frequencies for $\mathrm{Zn}_{1-\mathrm{x}} \mathrm{Li}_{0.5 \mathrm{x}} \mathrm{Fe}_{2+0.5 \mathrm{x}} \mathrm{O}_{4}$.

Table 1: Variation of the temperature parameter $d$ with the composition at different selected frequencies.

\begin{tabular}{ccccccc}
\hline \multirow{2}{*}{$\mathrm{x}$} & $\mathrm{d}$ & & & & & \\
\cline { 2 - 7 } & $100 \mathrm{~Hz}$ & $1 \mathrm{kHz}$ & $10 \mathrm{kHz}$ & $100 \mathrm{kHz}$ & $1 \mathrm{MHz}$ & $5 \mathrm{MHz}$ \\
\hline 0.25 & 6.36 & 7.09 & 7.05 & 7.01 & 6.86 & 6.57 \\
\hline 0.5 & 5.78 & 6.97 & 6.76 & 6.48 & 6.11 & 5.96 \\
\hline 0.75 & 5.49 & 6.2 & 6.08 & 6.02 & 5.84 & 5.56 \\
\hline 1 & 14.1 & 14.3 & 13.4 & 12.5 & 10.1 & 8.36 \\
\hline
\end{tabular}

Figure (5) shows the variation of the dielectric constant $\varepsilon^{\prime}$ with the frequency as log-log scale at different temperatures for $\mathrm{Zn}_{1-\mathrm{x}} \mathrm{Li}_{0.5 \mathrm{x}} \mathrm{Fe}_{2+0.5 \mathrm{x}} \mathrm{O}_{4}$. It is shown that the behavior of the dielectric constant with the frequency is normal, i.e., $\varepsilon^{\prime}$ decreases with increasing frequency. Also the variation of $\varepsilon^{\prime}$ with the frequency exhibits a peaking features for the samples with $\mathrm{x}=0.25,0.5$, and 0.75. The peaks are shifted towards lower frequencies with increasing 
temperature. As the temperature increases, the dielectric constant increases. The values of the dielectric constant are very high and decreases rapidly with increasing frequency. With increasing $\mathrm{Li}$ ion content, the dielectric constant decreases. It is well known that the complex dielectric constant $\left(\varepsilon^{*}=\varepsilon^{\prime}+\mathrm{j} \varepsilon^{\prime \prime}\right)$ of the medium vary with the angular frequency $\omega(=2 \pi f)$ according to the following equation $[13,18]$.
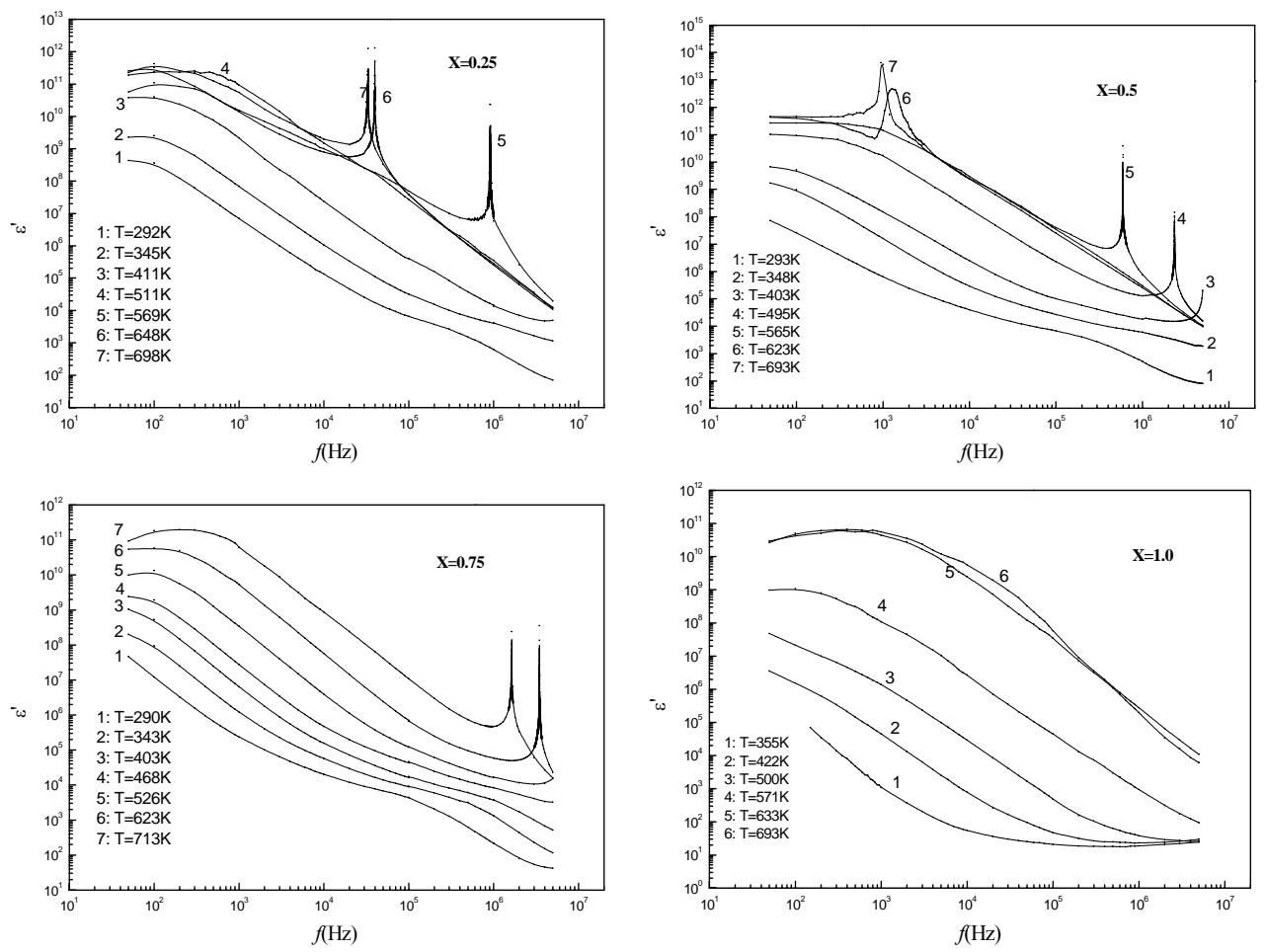

Fig. (5) : The variation of dielectric constant, $\varepsilon^{\prime}$, with the frequency at different temperatures for $\mathrm{Zn}_{1-\mathrm{x}} \mathrm{Li}_{0.5 \mathrm{x}} \mathrm{Fe}_{2+0.5 \mathrm{x}} \mathrm{O}_{4}$.

$$
\varepsilon^{*}=\varepsilon_{\infty}+\frac{\left(\varepsilon_{o}-\varepsilon_{\infty}\right)}{(1+j \omega \tau)}
$$

where $\tau$ is the relaxation time, $\varepsilon_{0}$ is the static field dielectric constant, and $\varepsilon_{\infty}$ is the high-frequency (optical) dielectric constant of the material. The real and imaginary parts of the complex dielectric constant $\varepsilon^{\prime}, \varepsilon^{\prime \prime}$ respectively can be expressed as [13].

$$
\varepsilon^{\prime}=\varepsilon_{\mathrm{o}}+\frac{\left(\varepsilon_{\mathrm{o}}-\varepsilon_{\infty}\right)}{\left(1+\omega^{2} \tau^{2}\right)}
$$


and

$$
\varepsilon^{\prime \prime}=\left(\varepsilon_{0}-\varepsilon_{\infty}\right)+\frac{\omega \tau}{\left(1+\omega^{2} \tau^{2}\right)}
$$

Equation (6) gives an explanation to the decrease of the dielectric constant with the frequency. From the other hand, the behavior of dielectric constant with the frequency can be explained on the fact that the hopping of the charge carriers can not follow the frequency of the external applied electric field beyond a certain frequency value [19]. $\varepsilon^{\prime \prime}$ represents the dielectric loss through the material.

The variation of the dielectric constant with the temperature at different selected frequencies $\left(10^{2} 10^{3}, 10^{4}, 10^{5}, 10^{6}, 5 \times 10^{6} \mathrm{~Hz}\right)$ is shown in Fig. (6), for all samples. It is shown that the dielectric constant increases with increasing temperature as the case of AC electrical conductivity with the temperature. This behavior may be attributed to the existence of strong correlation between conduction mechanism and dielectric polarization in ferrite [20-22].
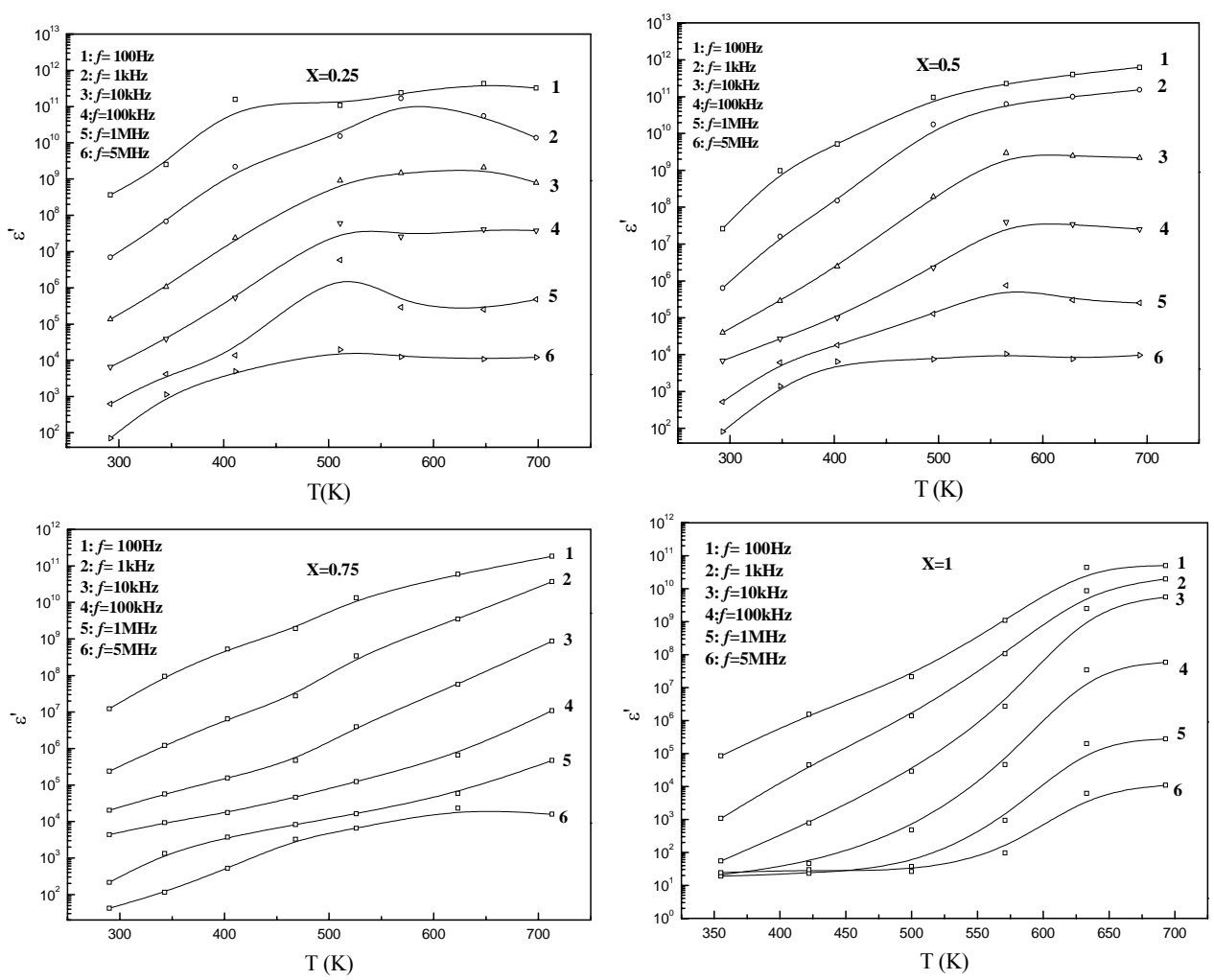

Fig. (6): The variation of the dielectric constant with temperature at different selected frequencies for $\mathrm{Zn}_{1-\mathrm{x}} \mathrm{Li}_{0.5 \mathrm{x}} \mathrm{Fe}_{2+0.5 \mathrm{x}} \mathrm{O}_{4}$. 
A very important quantity is the dielectric loss tangent, $\tan \delta$, which measures directly the phase difference due to loss of energy within the sample at a particular frequency [23]. Tan $\delta$ is given by

$$
\tan \delta=\frac{\varepsilon^{\prime \prime}}{\varepsilon^{\prime}}
$$

The Variation of dielectric loss tangent $\tan \delta$ with the frequency at different temperatures for all prepared samples is shown in Fig. (7). It is shown that the dielectric loss tangent exhibits a peaking behavior with the frequency. The peaks are shifted towards higher frequencies with increasing temperature. The appearance of the peaks in $\tan \delta$ versus the frequency curve can be explained on the basis of the previous assumption [20-22] that a strong correlation exists between the conduction mechanism and the dielectric polarization of ferrite. In this case the peaks in $\tan \delta$ curves are observed when the hopping frequency of charge carriers coincides with that of the external electric field [19]. The shift of the maximum of $\tan \delta(f)$ curves to higher frequencies with increasing temperature is due to the increase of hopping frequency of the charge carriers with increasing temperature. In this case
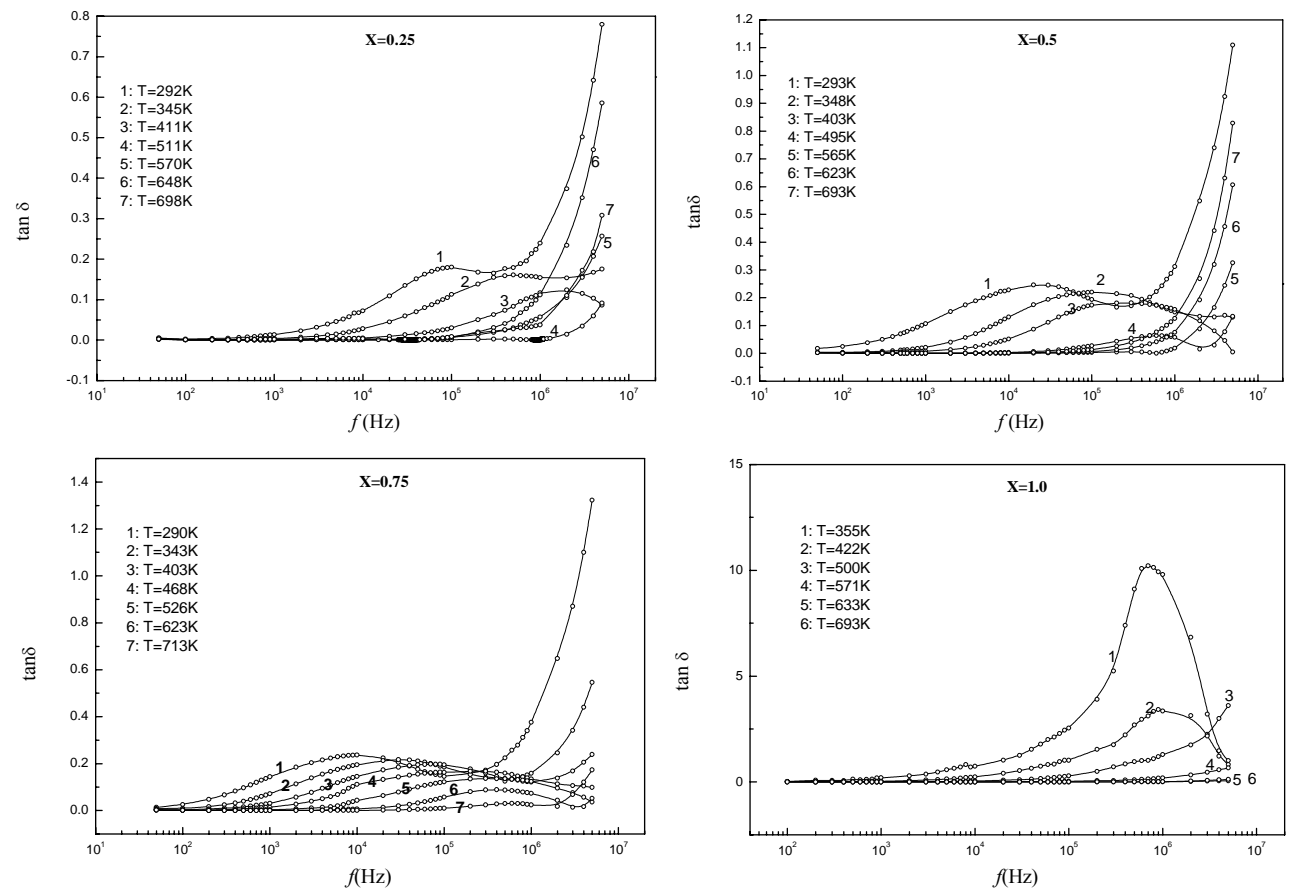

Fig. (7): The variation of the tan $\delta$ with the frequency at different selected temperatures for $\mathrm{Zn}_{1-\mathrm{x}} \mathrm{Li}_{0.5 \mathrm{x}} \mathrm{Fe}_{2+0.5 \mathrm{x}} \mathrm{O}_{4}$. 


$$
\omega \tau=1
$$

where $\tau$ is the relaxation time of the hopping process and $\omega$ is the angular frequency of the external field ( $\left.\omega=2 \pi f_{\max }\right)$ [24-26]. The relaxation time $\tau$ can be written as [27] .

$$
\tau=\tau_{\mathrm{o}} e^{E /(\mathrm{kT})}
$$

where $\tau_{\mathrm{o}}$ is the relaxation time at infinity high temperature, $E_{\mathrm{D}}$ is the activation energy for dielectric relaxation, and $k$ is Boltzmann constant. Fig. (8), shows the logarithmic representation of the relaxation time $\tau$ versus $10^{3} / T$ for the samples with $\mathrm{x}=0.25,0.5$, and 0.75 . Each sample exhibits a straight line with slope equal to $E_{\mathrm{D}} / k$. Table (2) shows the values of the dielectric activation energy $\mathrm{E}_{\mathrm{D}}$. The activation energy of the dielectric relaxation $E_{\mathrm{D}}$ lies between 0.208 to 0.261 $\mathrm{eV}$.

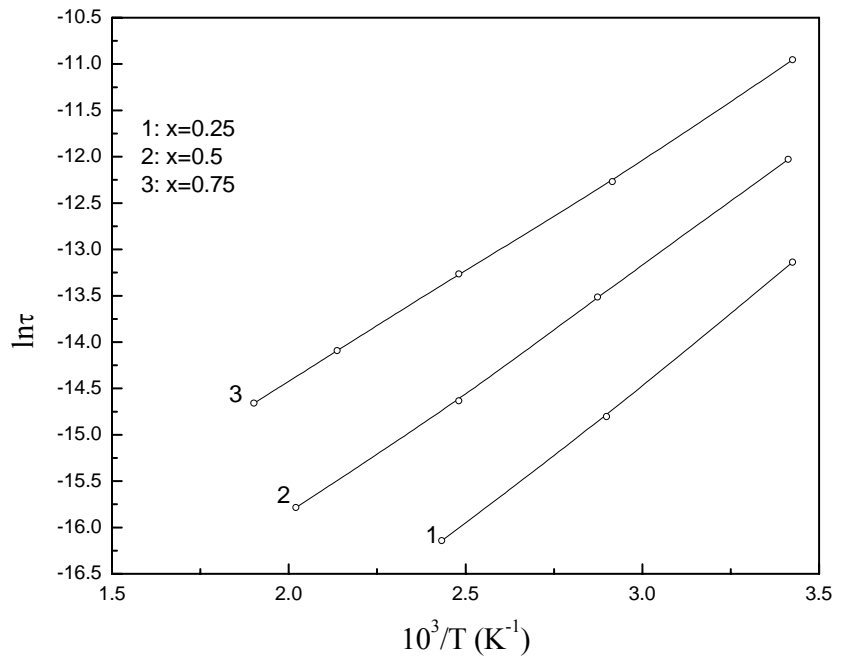

Fig. (8): The variation of $\ln \tau$ with the temperature $\left(10^{3} / T\right)$ for $\mathrm{Zn}_{1-\mathrm{x}} \mathrm{Li}_{0.5 \mathrm{x}} \mathrm{Fe}_{2+0.5 \mathrm{x}} \mathrm{O}_{4}$.

Table (2): The dielectric activation energy $\mathrm{E}_{\mathrm{D}}$ for $\mathrm{Zn}_{1-\mathrm{x}} \mathrm{Li}_{0.5 \mathrm{x}} \mathrm{Fe}_{2+0.5 \mathrm{x}} \mathrm{O}_{4}$.

\begin{tabular}{cccc}
\hline $\mathrm{x}$ & 0.25 & 0.5 & 0.75 \\
\hline $\mathrm{E}_{\mathrm{D}}(\mathrm{eV})$ & 0.261 & 0.234 & 0.208 \\
\hline
\end{tabular}




\section{Conclusion:}

Four samples of the composition $\mathrm{Zn}_{1-\mathrm{x}} \mathrm{Li}_{0.5 \mathrm{x}} \mathrm{Fe}_{2+0.5 \mathrm{x}} \mathrm{O}_{4}$ were prepared by the ceramic method. AC electrical conductivity and the dielectric constant were measured at different temperature and frequencies. The results show that, the values of the dielectric constant are abnormally very high $\left(10^{11}-10^{13}\right)$ at room temperature. AC electrical conductivity shows semiconducting behavior with the temperature. Many conduction mechanisms were tested, but the multiple hopping conduction mechanism seems to be the most favorable conduction mechanism in these samples.

\section{References}

1. B.K. Kuanr, G.P. Srivastava, J. Appl. Phys. 75 (10), 6115 (1994).

2. S.A. Mazen, A. Elfalaky, A.Z. Mohamed, H.A. Hashem, Mater. Chem. Phys. 44, 293 (1996).

3. C.S. Liu, W.B. Shu, M.J. Tung, M.Y. Ke, J. Appl. Phys. 67, 5506 (1990).

4. F.J.C.M. Toolonaar, M.T.J. Vanlierop Verhees, J. Mater. Sci. 24, 402 (1989).

5. P.V. Reddy, T.S. Rao, J. Less-Common Met. 79, 191 (1981).

6. S.A. Mazen, Phys. Stat. Sol. (a) 154, 681 (1996).

7. A. Ahmed, J. Mater. Sci. 27, 4120 (1992).

8. S.A. Mazen, F. Metawe, S.F. Mansour, J. Phys. D: Appl. Phys. 30, 1799 (1997).

9. S.M. Attia, A.M. Abo El Ata, D. El Kony, J. Magn. Magn. Mater. 270, 142 (2004).

10. A.M. Abo El Ata, S.M. Attia, T.M. Meaz, Solid State Sciences 6, 61 (2004).

11. C.G. Koops, Phys. Rev. 83 (1), 121 (1951).

12. S.A. Mazen, H.M. Zaki, J. Phys. D: Appl. Phys. 28, 1 (1995).

13. A. Jonscher, Dielectric Relaxation in Solids, Chelsea Dielectric Press, London, (1983).

14. T.M. Meaz, S.M. Attia, A.M. Abo El Ata, J. Magn. Magn. Mater. 257, 296 (2003).

15. S.R. Elliott, Adv. Phys. 36, 135 (1987).

16. S. Abboudy, R. Mansfield, P. Foozoni, Proceedings of the International Conference: High Magnetic Fields in Semiconductor Physics III, in: G. Landwehr (Ed.), Springer Series in Solid-State Sciences, 101, 482 Springer, Berlin, (1992),

17. S. Abboudy, M.A. Ahmed, A.M. Abo El Ata, Phys. Low-Dim. Struct. 5/6, 107 (2001).

18. W.D. Kingery, H.K. Bouen, D.R. Ublmanm, in: Introduction to Ceramics, 2nd Edition, Wiley, New York, (1976). 
19. V.R.K. Murthy, J. Sobhamadri, Phys. Status Solidi A 36, 133 (1976).

20. N. Rezlescu, E. Rezlescu, Phys. Status Solidi A 59, 323 (1980).

21. K. Iwauchi, J. Appl. Phys. 10, 1520 (1971).

22. M. K. Fayek, S. S. Ata-Allah, H. A. Zayed, M. Kaiser, S. M. Ismail, J. Alloys. Comp., 469, 9 (2009).

23. M. M. El-Desoky and I. Kashif, Phys. Stat. Sol., 194, No. 1, 89 (2002).

24. A. K. Jonscher, Dielectric Relaxation in Solids, Page 128, Chelsea Dielectrics Press Ltd. London (1983).

25. A. Zaky and R. Hawley "Dielectric Solids" First Published (1970) in Great Britain by Routledge \& Kegan Pawl Ltd. And in the USA by Dover Publications Inc. New York.

26. M.B. Reddy, P.V. Reddy, Phys. D: Appl. Phys. 24, 975 (1991).

27. K. Standly, Oxide Magnetic Materials, Clarendon Press, Oxford, 114 (1974). 